\title{
Label-free impedimetric immunosensor for detection of the textile azo dye Disperse Red 1 in treated water
}

\author{
Carolina G. Rocha*, Antonio A.P. Ferreira, Hideko Yamanaka \\ São Paulo State University (UNESP), Institute of Chemistry, Department of Analytical Chemistry, Rua Professor Francisco Degni, 55, 14.800-060, \\ Araraquara, SP, Brazil
}

\section{A R T I C L E I N F O}

\section{Article history:}

Received 23 December 2015

Received in revised form 4 May 2016

Accepted 7 May 2016

Available online 10 May 2016

\section{Keywords:}

Immunosensor

Electrochemical impedance spectroscopy

Azo dyes

Disperse Red 1

\begin{abstract}
A B S T R A C T
The development of methodologies to detect and quantify azo dyes in treated water is required because some of these dyes exhibit genotoxic activity, even at low concentrations. Here, the construction and characterization of an impedimetric immunosensor for determination of the textile azo dye Disperse Red 1 (DR1) by means of a label-free assay is reported. Anti-DR1 antibodies (Ab anti-DR1) were successfully coupled to glassy carbon electrode (GCE) surface by bonding using electrochemically generated activated carboxylic groups. The concentration of DR1 was measured by the increase in charge transfer resistance $\left(R_{C T}\right)$ when the immune reaction occurred, using $\mathrm{Fe}(\mathrm{CN})_{6}{ }^{3-/ 4-}$ as a probe. Electrochemical characterizations of the sensor by cyclic voltammetry (CV) and electrochemical impedance spectroscopy (EIS) were performed, and infra-red spectra were obtained to complement the electrochemical results showing immobilization of the antibodies. Under optimal conditions, the change in $\mathrm{R}_{\mathrm{CT}}$ presented a linear relationship with DR1 concentration in the range from 8.40 to $100 \mathrm{nM}$, and the sensor provided low limit of detection $(\mathrm{LOD}=2.52 \mathrm{nM})$ and quantification $(\mathrm{LOQ}=8.40 \mathrm{nM})$. No significant interference from other azo dyes was observed. The performance of the immunosensor was evaluated using tap water spiked with 20.0 nM DR1 and a satisfactory recovery of $98.5 \%$ was found. The proposed immunosensor is simple, relatively inexpensive, and shows good sensitivity for this application.
\end{abstract}

(C) 2016 Published by Elsevier B.V.

\section{Introduction}

Azo dyes, which contain one or more $-\mathrm{N}=\mathrm{N}$ - groups in their structures [1], are widely used in the textile industry because they provide a method of dyeing cellulosic fibres (especially elongated fibres) with a high degree of attachment and high resistance against light and humidity, compared to other classes of dyes [2]. Precisely due to these features, the treatment of wastewater containing azo dyes is difficult, and conventional biological processes can be ineffective because the compounds are not biodegradable. In addition, their reductive cleavage can release aromatic amines that are more toxic than the dyes themselves [3].

Investigations using microorganisms and mammalian cells have shown that many of these dyes present genotoxic activity [4]. This activity is closely related to the nature and position of the substituents attached to the azo group [5]. Therefore, since small variations in dye molecules change their properties, it is impor-

\footnotetext{
* Corresponding author.

E-mail addresses: carolgomesrocha@hotmail.com.br, carolgrlim@gmail.com (C.G. Rocha).
}

tant that each azo dye be studied individually [6]. Azo dyes become mutagenic after breaking of the azo bonds by azoreductase enzymes synthesized in the intestinal cells, which results in colourless aromatic amines [7,8]. Uliana et al. [9] investigated the interaction between DNA and two disperse azo dyes, Disperse Red 1 (DR1) and Disperse Orange 1, as well as their electrolysis products, and found that after interaction there were strong decreases in the current intensities of DNA bases. It was concluded that the dyes affected the double helix structure of DNA, causing conformational changes and damage.

In addition to the problems of toxicity of azo dyes, the presence of these coloured substances in natural waters affects light penetration and can interfere in the biological cycles of aquatic biota, especially in relation to the photosynthesis process and oxygenation of the water body [10]. Therefore, considering that about $50 \%$ of the dyes are lost after the dyeing process and aobut $10-15 \%$ of them are discharged in the effluents [11], it is very important that methods for the determination of these substances be developed for the purposes of water quality control.

Several methods for detection of azo dyes have been reported in the literature, especially high performance liquid chromatography (HPLC) coupled to different detectors [12-15], as well as capillary 
Table 1

Limits of detection obtained with different techniques for dyes determination.

\begin{tabular}{|c|c|c|c|}
\hline Dye & LOD & Technique & Reference \\
\hline $\begin{array}{l}\text { Biodegradation products of an } \\
\text { antraquinone dye, Drimarene } \\
\text { Blue } K_{2} R L\end{array}$ & $0.011-0.1 \mu \mathrm{g} \mathrm{mL}^{-1}$ & HPLC with fluorescence detector & 12 \\
\hline $\begin{array}{l}\text { Acid Orange } 6 \text { Acid Orange } 7 \\
\text { Acid Orange } 20 \text { Acid Orange } 52 \\
\text { Basic Orange } 22 \text { Basic Orange } \\
21 \text { Basic Orange } 2\end{array}$ & $0.5-3.0 \mu \mathrm{g} \mathrm{kg}^{-1}$ & HPLC-MS/MS & 13 \\
\hline $\begin{array}{l}\text { Dyes present in historical art } \\
\text { works }\end{array}$ & - & HPLC with a dual detection system UV-vis and ESI MS & 14 \\
\hline $\begin{array}{l}\text { Ponceau 4RC Sunset yellow } \\
\text { Allura red Azophloxine } \\
\text { Ponceau xylidine Erythrosine } \\
\text { Orange II }\end{array}$ & $0.02-21.83 \mathrm{ng} \mathrm{mL}^{-1}$ & HPLC-DAD-MS HPLC-MS/MS & 15 \\
\hline Green S Patent Blue & $10-17 \mu \mathrm{M}$ & Capillary electrophoresis & 16 \\
\hline Ponceau 4R & $0.80 \mathrm{ng} \mathrm{mL}^{-1}$ & ELISA & 17 \\
\hline Amaranth & $3.35 \mathrm{ng} \mathrm{mL}^{-1}$ & ELISA & 18 \\
\hline Sunset yellow Tartrazine & $1.25-1.43 \times 10^{-8} \mathrm{M}$ & Differential pulse voltammetry & 19 \\
\hline $\begin{array}{l}p \text {-Phenylenediamine } \\
\text { Resorcinol }\end{array}$ & $0.58-0.79 \mathrm{mg} \mathrm{L}^{-1}$ & Linear sweep voltammetry & 20 \\
\hline 2,6-Diaminopyridine & $0.0275 \mathrm{mg} \mathrm{kg}^{-1}$ & Cyclic voltammetry & 21 \\
\hline Sudan I & $0.03 \mathrm{ng} \mathrm{mL}^{-1}$ & EIS & 22 \\
\hline Disperse Orange 1 & $7.56 \mathrm{nM}$ & EIS & 23 \\
\hline Disperse Red 1 & $2.52 \mathrm{nM}$ or $0.79 \mathrm{ng} \mathrm{mL}^{-1}$ & EIS & this work \\
\hline
\end{tabular}

electrophoresis [16], and enzyme-linked immunosorbent assay (ELISA) $[17,18]$. However, many of these processes may require long analysis times and/or substantial financial resources. For this reason, electrochemical sensors represent a viable alternative for analysis of dyes [19-23], offering advantages including simplicity, speed, high sensitivity, and lower costs. Methods for determination of azo dyes using different techniques are listed in Table 1.

Among the different types of electrochemical sensors, impedimetric immunosensors represent a category that deserves special attention. Immunosensors can be highly selective, due the specificity of antigen-antibody interactions, and their use in combination with the electrochemical impedance spectroscopy (EIS) technique enables the development of label-free assays. Formation of the immunocomplex changes the impedance response of the system, compared to the response prior to the immunoaffinity reaction, providing the basis of the analytical methodology and eliminating the use of indirect measures. This makes the sensor simpler and cheaper, because the assay requires fewer steps and dispenses with the use of labelled secondary antibodies. Furthermore, EIS is a non-destructive technique that allows successive measurements to be made using the same electrode. All these advantages have led to increased interest in impedimetric immunosensors in recent years, and several different applications have been reported [24-26], although few are related to dye determination.

In order to ensure sensitivity and stability of an immunosensor, the antibodies must be suitably immobilized on the transducer and maintain their biological activity after the immobilization process [27]. Procedures that satisfy these requirements include the use of self-assembled monolayers on gold $[28,29]$ and carbon surfaces [23,30], functionalized nanoparticles [31,32], and polymeric films $[33,34]$. It is also possible to perform the immobilization of a biomolecule by means of groups generated directly on the glassy carbon electrode surface, instead of using additional reagents to fulfil this role in the assay. Millan and Mikkelsen [35] described a method in which a glassy carbon electrode was oxidized by the application of a high potential in a strongly oxidizing solution (acid solution of potassium dichromate). This procedure led to the formation of carboxylic groups on the glassy carbon electrode surface itself, which were then activated with EDC/NHS (1-ethyl-3-(3dimethylaminopropyl) carbodiimide and N-hydroxy-succinimide), promoting the bond to the DNA molecule. Because it is very simple and effective, this method can be used to immobilize biomolecules such as antibodies on carbon surfaces, and for this reason was used in the present work. The methodology was previously explored for the immobilization of proteins [36].

In this paper, we propose the development and characterization of an impedimetric immunosensor for detection of the textile azo dye Disperse Red 1 (DR1) in treated water; as shown in Table 1 no determination of DR1 was reported. A GCE electrode was electrochemically oxidized, activated with EDC/NHS, and anti-DR1 antibodies were covalently linked to the electrode surface. The interaction was carried out using EIS in the presence of $\mathrm{Fe}(\mathrm{CN})_{6}{ }^{3-14-}$ as an electrochemical probe. The very simple proposed immunosensor was then applied in the analysis of tap water samples.

\section{Materials and methods}

\subsection{Reagents and solutions}

The reagents potassium hexacyanoferrate (III), N-hydroxysuccinimide (NHS), $\mathrm{KH}_{2} \mathrm{PO}_{4}, \mathrm{NaCl}, \mathrm{KCl}, \mathrm{K}_{2} \mathrm{Cr}_{2} \mathrm{O}_{7}$, ethanolamine hydrochloride, and acetonitrile were purchased from Sigma. Potassium hexacyanoferrate (II), $\mathrm{Na}_{2} \mathrm{HPO}_{4}$, nitric acid (69-70\%), and sulphuric acid (95-98\%) were purchased from J. T. Baker. The dyes Disperse Red 1 (DR1), Disperse Orange 1 (DO1), Disperse Red 73 (DR73), and Disperse Red 78 (DR78) were purchased from Aldrich. The 1-ethyl-3-(3-dimethylaminopropyl) carbodiimide (EDC) reagent was purchased from Fluka. The anti-DR1 monoclonal antibodies (Ab anti-DR1) were purchased from Rheabiotech (Campinas, Brazil). All aqueous solutions were prepared using Milli-Q water with resistivity of $18.2 \mathrm{M} \Omega \mathrm{cm}$ (Millipore). All other chemicals were analytical grade.

A stock solution of DR1 $(1.0 \mathrm{mM})$ was prepared in a mixture of acetonitrile and deionized water $(1: 1, \mathrm{v} / \mathrm{v})$. $0.1 \mathrm{M}$ phosphate buffered saline (PBS, $0.1 \mathrm{M} \mathrm{NaCl}, \mathrm{pH} 7.4$ ) was used to prepare the stock solution of Ab anti-DR1 and for dilution of the DR1 stock solution.

\subsection{Preparation of the immunosensor}

A glassy carbon electrode (GCE) (3.0 mm diameter) was carefully polished with $0.05 \mu \mathrm{m}$ alumina $\operatorname{powder}\left(\gamma-\mathrm{Al}_{2} \mathrm{O}_{3}\right)$ on chamois 


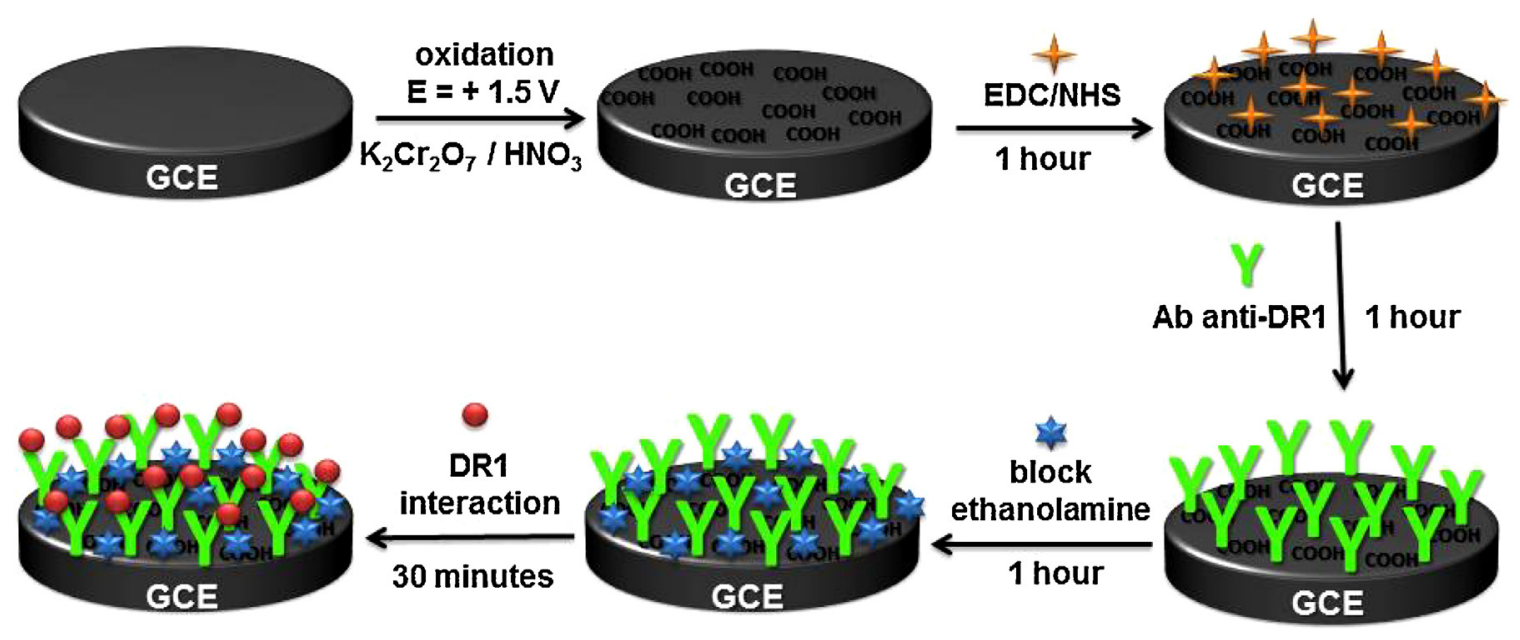

Fig. 1. Schematic illustration of the GCE modification procedure used to construct the impedimetric immunosensor.

leather for $3 \mathrm{~min}$. The electrode was then washed and ultrasonically cleaned (for $1 \mathrm{~min}$ ) in ethanol, followed by water, and dried in air.

After cleaning, the GCE was submitted to an electro-oxidation in order to generate carboxylic groups covering the entire surface. A potential of $+1.5 \mathrm{~V}$ was applied for $15 \mathrm{~s}$ in a solution of potassium dichromate $2.5 \%(\mathrm{~m} / \mathrm{m})$ containing $10 \%$ nitric acid $(\mathrm{m} / \mathrm{m})$. The electrode was then rinsed with water and immediately incubated upside down over a drop $(100 \mu \mathrm{L})$ of EDC/NHS solution (5.0 and $8.0 \mathrm{mM}$, respectively) for $1 \mathrm{~h}$ at room temperature.

After the incubation, the electrode was rinsed by immersion in deionized water, with moderate stirring, for three sets of $10 \mathrm{~s}$, and then incubated for $1 \mathrm{~h}$ in $50 \mu \mathrm{L}$ of $\mathrm{Ab}$ anti-DR1 solution $\left(0.05 \mathrm{mg} \mathrm{mL}^{-1}\right)$. The weakly bonded antibody molecules were removed by immersing the electrode in PBS buffer solution $(0.1 \mathrm{M}$, $\mathrm{pH} 7.4$ ), with moderate stirring, for three sets of $10 \mathrm{~s}$.

The remaining activated carboxylic groups (which were not used for binding to the antibody) were blocked by incubation in $100 \mu \mathrm{L}$ of ethanolamine solution $(100 \mathrm{mM})$, followed by washing by immersion in PBS (0.1 M, pH 7.4). After this step, the electrode was ready for the interaction with the antigen (DR1 dye).

To avoid evaporation of the drops of solutions used in each modification step, the electrode was fixed upside down in a microcentrifuge tube containing the solution and covered with Parafilm. Fig. 1 summarizes the GCE modification methodology used to construct the immunosensor.

\subsection{Cyclic voltammetry (CV) and electrochemical impedance spectroscopy (EIS) measurements}

All electrochemical measurements were carried out with a glassy carbon electrode $\left(A_{\text {geom }}=0.0707 \mathrm{~cm}^{2}\right), \mathrm{Ag}|\mathrm{AgCl}| \mathrm{KCl}_{\text {sat }}$ electrode, and a platinum wire $\left(A_{\text {geom }}=4 \mathrm{~cm}^{2}\right)$ as the working, reference, and auxiliary electrodes, respectively. The measurements were performed in the presence of $0.1 \mathrm{M}$ PBS buffer solution ( $\mathrm{pH} 7.4$ ) containing $1 \mathrm{mM}$ of $\mathrm{Fe}(\mathrm{CN})_{6}{ }^{3-/ 4-}$ as a probe. The cyclic voltammetry (CV) measurements used a compact potentiostat/galvanostat ( $\mu$ Autolab Type III), with General Purpose Electrochemical System v. 4.9 (GPES) software for data acquisition and processing. Characterization of each step of construction of the immunosensor was performed with scanning from -0.2 to $+0.6 \mathrm{~V}$, at a scan rate $(v)$ of $25 \mathrm{mV} \mathrm{s}^{-1}$.

The electrochemical impedance (EIS) measurements were performed using a compact modular potentiostat/galvanostat (Autolab PGSTAT204) fitted with an FRA32 M module and controlled using NOVA 1.10 software. The EIS measurements were performed inside
A

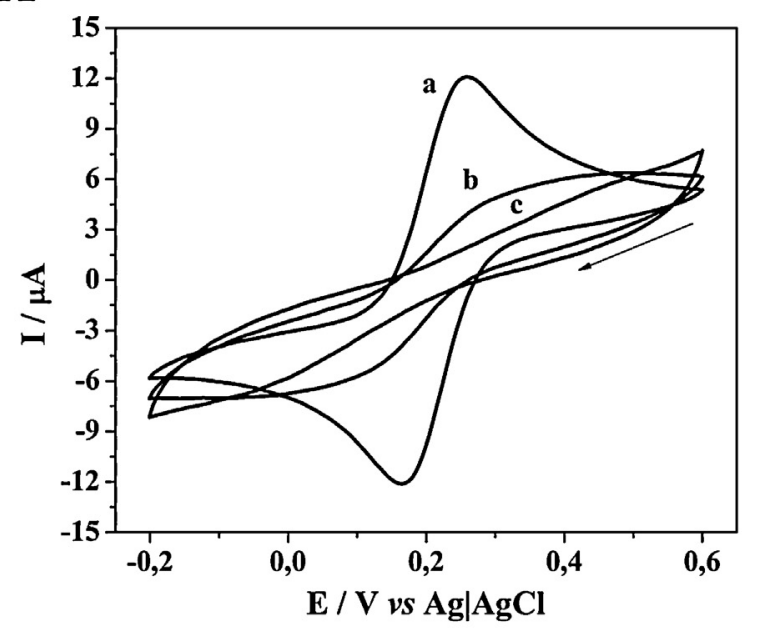

B

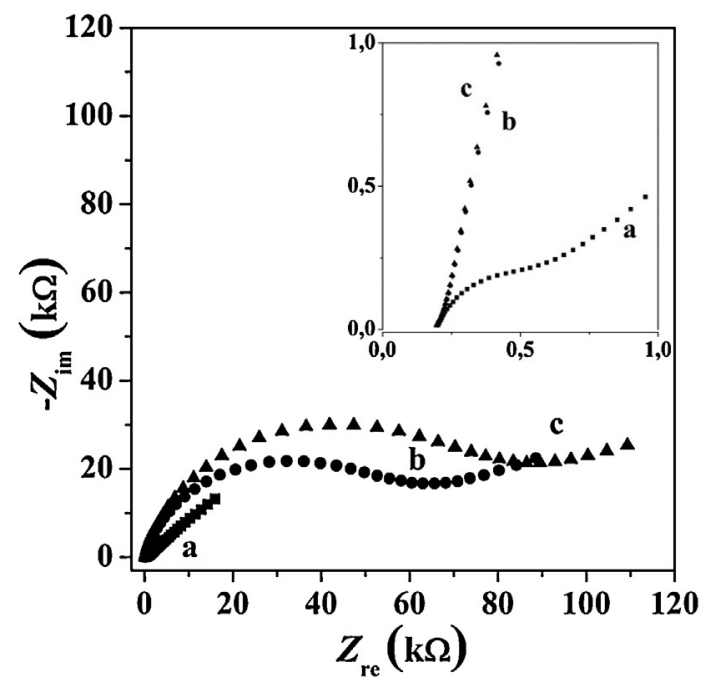

Fig. 2. (A) Cyclic voltammograms and (B) Nyquist plots for (a) bare GCE, (b) Ab anti-DR1/GCE, and (c) ethanolamine/Ab anti-DR1/GCE. Both characterizations were performed using $0.1 \mathrm{M}$ PBS buffer solution ( $\mathrm{pH} 7.4$ ) containing $1 \mathrm{mM}$ of $\mathrm{Fe}(\mathrm{CN})_{6}{ }^{3-/ 4-}$. Inset: High frequency region. 
Table 2

Experimental parameters evaluated using full factorial design.

\begin{tabular}{|c|c|c|}
\hline Variable & Low Level & High Level \\
\hline$[\mathrm{Ab} \text { anti-DR1] }]^{\mathrm{a}}$ & $0.005 \mathrm{mg} \mathrm{mL}^{-1}$ & $0.05 \mathrm{mg} \mathrm{mL}^{-1}$ \\
\hline $\mathrm{Ab}$ incubation time ${ }^{\mathrm{b}}$ & $30 \mathrm{~min}$ & $60 \mathrm{~min}$ \\
\hline $\mathrm{Ag}$ incubation time $\mathrm{c}^{\mathrm{C}}$ & $30 \mathrm{~min}$ & $60 \mathrm{~min}$ \\
\hline
\end{tabular}

a Faraday cage (EG\&G Instruments, Princeton Applied Research). The EIS technique was employed for characterization and for the determination of DR1 concentrations, using a frequency range from $50 \mathrm{KHz}$ to $10 \mathrm{mHz}$ and an amplitude of $10 \mathrm{mV}$ (rms). The experimental impedance data were presented as Nyquist plots and the diameter of the semicircle, which was dependent on the charge transfer resistance $\left(R_{C T}\right)$, was then used to obtain the quantitative sensing signal for the DR1 concentration.

2.4. Characterization of immobilization of the antibody on the glassy carbon surface, using attenuated total reflectance fourier transform infra-red spectroscopy (ATR-FTIR)

The glassy carbon surface, bare and after the immobilization of $\mathrm{Ab}$ anti-DR1, was additionally characterized by means of a nonelectrochemical technique (ATR-FTIR). For this purpose, a glassy carbon plate with dimensions of $2 \times 2 \mathrm{~cm}$ and $0.5 \mathrm{~cm}$ thickness was carefully polished with $0.05 \mu \mathrm{m}$ alumina powder $\left(\gamma-\mathrm{Al}_{2} \mathrm{O}_{3}\right)$ on chamois leather for $3 \mathrm{~min}$, washed with ethanol and water, and dried in air.

The immobilization of Ab anti-DR1 on the glassy carbon plate was performed using the same procedure described for the GCE. Infra-red spectra was then obtained with a Nicolet iS5 FT-IR spectrometer (Thermo Scientific) equipped with an iD7 ATR accessory module.

\subsection{Optimization of experimental conditions for construction of the immunosensor using full factorial design}

Factorial design is a simultaneous method in which the factors of interest are evaluated at the same time. It can be represented by $\mathrm{b}^{\mathrm{k}}$, where $\mathrm{k}$ is the number of factors and $\mathrm{b}$ is the number of levels selected [37]. Here, chemometric studies using full factorial design were conducted in order to optimize the experimental conditions for construction of the immunosensor. The stages that showed the greatest impact on the signal measured after interaction with the analyte were selected.

The following factors were evaluated: Ab anti-DR1 concentration, incubation time in Ab anti-DR1 solution, and incubation time in DR1 solution (antigen), at high and low levels. Table 2 summarizes the conditions investigated in this study.

The procedure required eight experiments $\left(2^{3}=8\right)$, which in triplicate mean 24 experiments in total. The DR1 concentration was fixed at $1 \times 10^{-7} \mathrm{M}$ in all cases. The change in the $R_{C T}$ value $\left(\Delta \mathrm{R}_{\mathrm{CT}}\right.$ ) between the measurements corresponding to the blocking step and the antigen interaction step in each experiment was used as the signal. The data were analyzed using Minitab ${ }^{\mathrm{TM}}$ statistical software in order to identify the effects on the system of the different combinations of factors.
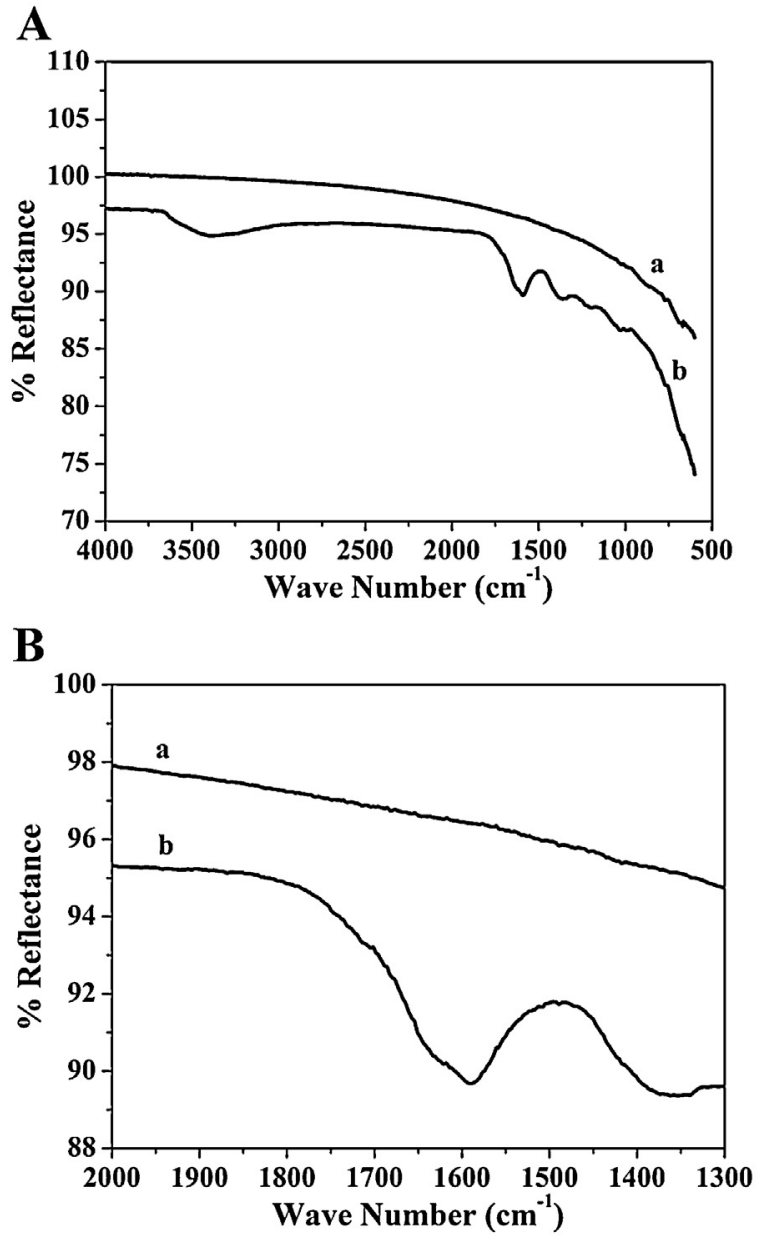

Fig. 3. (A) Infra-red spectra obtained for (a) the bare GCE and (b) the GCE with Ab anti-DR1. (B) Amplification of the spectral region related to the band corresponding to the amide group.

\section{Results and discussion}

\subsection{Electrochemical characterization}

The main steps of the immunosensor construction were electrochemically characterized by CV and EIS, as shown in Figs. 2(A) and $2(B)$, respectively. The cyclic voltammogram obtained for the bare GCE presented the typical profile obtained in the presence of the $\mathrm{Fe}(\mathrm{CN})_{6}{ }^{3-/ 4-}$ redox couple, with current peaks at $+0.256 \mathrm{~V}$ (cathodic peak) and $+0.164 \mathrm{~V}$ (anodic peak), as expected for a quasireversible electron transfer model $\left(\mathrm{I}_{\mathrm{pa}} / \mathrm{I}_{\mathrm{pc}} \neq 1.0\right.$ and $\Delta \mathrm{E}_{\mathrm{p}} \neq 59 \mathrm{mV}$, Fig. 2(A)). The $\mathrm{Fe}(\mathrm{CN})_{6}{ }^{3-/ 4-}$ redox couple does not exhibit an entirely reversible response in the presence of almost all phosphate buffer solutions (with $\mathrm{pH}$ around 7) and salt concentrations of around $0.1 \mathrm{M}$. The main reasons for this include changes in the diffusional control process in the electrode, phosphate adsorption on the electrode surface, and the influence of ohmic drop [38]. After antibody immobilization, it was possible to observe a decrease in the current peak intensities related to the redox couple, and an increase in $\Delta \mathrm{E}_{\mathrm{p}}$ (the $\Delta \mathrm{E}_{\mathrm{p}}$ values were $92 \mathrm{mV}$ for the bare electrode and $273 \mathrm{mV}$ after antibody immobilization).

These results indicated that something was bound to the electrode surface and hindered the redox couple electron transfer process. This could be attributed to attachment of the antibody molecules on the GCE surface. It can be seen from Fig. 2(A) that after the blocking step, there was a large change in the reversibility of the system, with virtually no peaks, which could be explained 
by the attachment of more species to the electrode surface, impeding the electron transfer. This was as expected, because in this step molecules of ethanolamine were present on the electrode.

Fig. 2(B) shows a successive increase in the charge transfer resistance $\left(R_{C T}\right)$ values according to the modification steps, reflected by the semicircle diameters. The $\mathrm{R}_{\mathrm{CT}}$ value for the bare GCE was 0.58 $\mathrm{k} \Omega$, while values of $58.91 \mathrm{k} \Omega$ and $81.22 \mathrm{k} \Omega$ were obtained for the GCE with Ab anti-DR1 and the blocked electrode, respectively. This indicated that species were successfully attached to the electrode surface, and that these species, in turn, progressively hindered the electron transfer process.

Therefore, both electrochemical characterization results indicated successful Ab anti-DR1 immobilization and blocking of the GCE surface. However, the electrochemical techniques did not provide any information concerning the identity of the substance present on the GCE surface, which therefore required the use of a different characterization technique.

\subsection{Characterization of antibody immobilization on the glassy carbon surface, using attenuated total reflectance Fourier transform infra-red spectroscopy (ATR-FTIR)}

The effective immobilization of the antibodies on the GCE surface was confirmed using infra-red spectroscopy, which can provide information concerning the functional groups present in the sample. The spectra obtained in this study are shown in Fig. 3.

In general, proteins (including antibodies) and peptides present broad bands that are difficult to differentiate, due to considerable overlap [39]. However, the spectra of all proteins exhibit absorption bands associated with their characteristic amide groups. The most useful infra-red bands for the characterization of proteins are those for amide I (related to carbonyl absorption) and amide II (related to the deformation of $\mathrm{NH}_{2}$ or $\mathrm{NH}$ ) [40], which occur near 1565 and $1655 \mathrm{~cm}^{-1}$, respectively.

The spectrum for the bare GCE (Fig. 3(A-a)) showed no significant features, while the spectrum for the GCE with immobilized antibody (Fig. 3(B-b)) showed a characteristic absorption band of amide groups. The absorption band in question occurred at $1580 \mathrm{~cm}^{-1}$, indicative of amide I. Furthermore, this band appeared to be superimposed on another band at around $1640 \mathrm{~cm}^{-1}$ (Fig. 3(Bb)) that could indicate the presence of amide II.

\subsection{Stability of the electrode containing immobilized $A b$ anti-DR1 after successive EIS measurements}

The stability of the immobilized antibody was evaluated using five EIS measurements performed in the presence of $0.1 \mathrm{M}$ PBS buffer solution ( $\mathrm{pH} 7.4$ ) containing $1 \mathrm{mM}$ of $\mathrm{Fe}(\mathrm{CN})_{6}{ }^{3-/ 4-}$.

Between the measurements, the electrode was incubated in PBS buffer solution (0.1 M, pH 7.4) for $30 \mathrm{~min}$ and rinsed with deionized water. The $\mathrm{R}_{\mathrm{CT}}$ values showed no significant differences between the measurements, with a relative standard deviation of $1.2 \%(n=5)$. The Nyquist plots corresponding to the measurement made immediately after the immobilization process and the last measurement were very similar, which excludes the possibility of molecules being leached from the GCE electrode during the measurements and the rinsing procedures. If the surface were not stable, the Nyquist plots would be expected to show the presence of inductive loops [41]. When the same experiments were carried out using a pencil graphite electrode (data not shown), no stability was achieved, probably due to the porosity of the electrode.

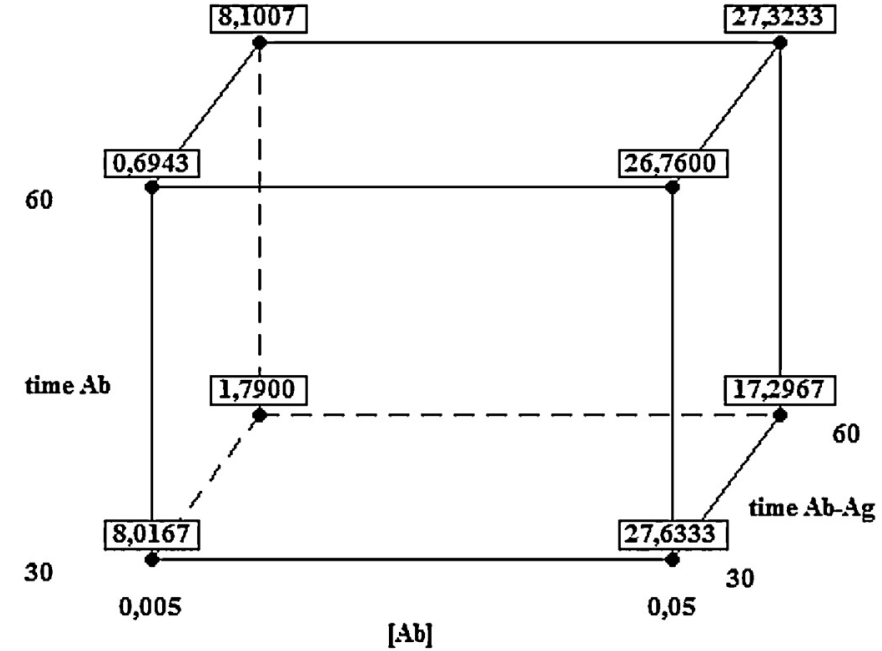

Fig. 4. Cube plot showing the relationship between the mean responses obtained in the EIS measurements $(n=3)$ and the different combinations of factors. The $\Delta R_{C T}$ values are presented multiplied by $1 \times 10^{3} \Omega(\mathrm{k} \Omega)$.

\subsection{Adsorption of DR1 on the blocked electrode surface (in the absence of $A b$ anti-DR1)}

Experiments were performed to investigate the effectiveness of ethanolamine in blocking the adsorption of DR1 on the GCE surface. The tests were conducted in the absence of Ab anti-DR1 (the carboxylic groups generated on the GCE surface were directly blocked with ethanolamine, without performing the antibody immobilization step), because this resulted in greater exposure of the surface for determination of the blocking capacity. The blocked electrode was incubated for $30 \mathrm{~min}$ in $1 \mu \mathrm{M}$ DR1 solution, then rinsed with water and used for the EIS measurements. The Nyquist plots obtained after the blocking step and after incubation with the DR1 solution were very similar, indicating that virtually no DR1 dye was adsorbed on the blocked electrode. In quantitative terms, there was an increase of $1.68 \mathrm{k} \Omega$ between the first and the last measurements, representing a $5.5 \%$ change in the impedance response. This change was very small, and could be considered acceptable because no antibodies were present. In the presence of antibodies, access to the electrode surface would become more difficult.

\subsection{Full factorial design optimization of the experimental conditions for immunosensor construction}

The results obtained with the chemometric study are presented in the form of a cube plot (Fig. 4). Each vertex of the cube corresponds to the mean of responses obtained in the measurements performed using the combination of parameters indicated by the convergent edges, which represent the factors of the factorial design. It can be seen from Fig. 4 that the highest signal $\left(\Delta \mathrm{R}_{\mathrm{CT}}\right)$ occurred for an $\mathrm{Ab}$ anti-DR1 concentration of $0.05 \mathrm{mg} \mathrm{mL}^{-1}$ (high level), incubation time in Ab solution of $30 \mathrm{~min}$ (low level), and incubation time in DR1 solution of $30 \mathrm{~min}$ (low level). Therefore, these conditions were adopted for construction of the immunosensor.

\subsection{Selectivity of the immunosensor response in the presence of other disperse dyes}

The selectivity of the anti-DR1 antibodies in the presence of other textile dyes was evaluated by individually incubating the immunosensor in $1.0 \times 10^{-7} \mathrm{M}$ solutions of Disperse Orange 1 (DO1), Disperse Red 73 (DR73), and Disperse Red 78/50 (DR78/50) 
$\mathbf{a}$<smiles>CCN(CCO)c1ccc(N=Nc2ccc([N+](=O)[O-])cc2)cc1</smiles>

b<smiles>CCN(c1ccccc1)c1ccc(/N=N/c2ccc([N+](=O)[O-])cc2)cc1</smiles>

c<smiles>CCN(CCC#N)c1ccc(N=Nc2ccc([N+](=O)[O-])cc2C#N)cc1</smiles>

d

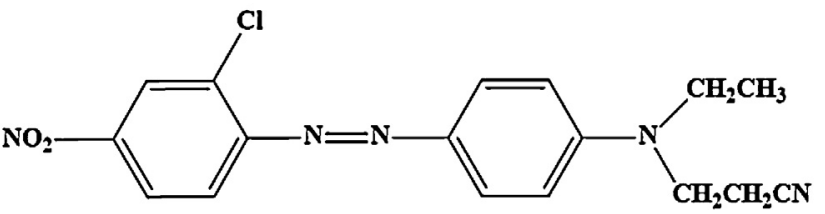

Fig. 5. Chemical structures of azo dyes: (a) DR1, (b) DO1, (c) DR73 and (d) DR78/50.

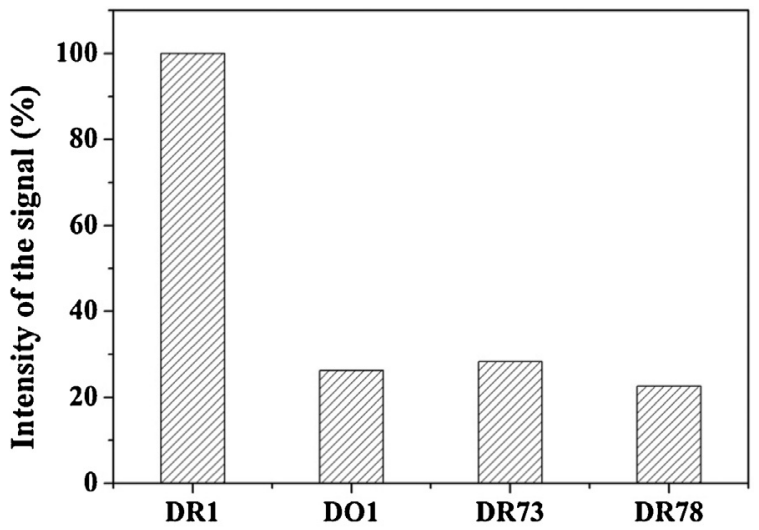

Fig. 6. Relative magnitudes of the signals obtained with the immunosensor after incubation in $1 \times 10^{-7} \mathrm{M}$ solutions of DR1, DO1, DR73, and DR78/50.

for $30 \mathrm{~min}$ at room temperature. These dyes were chosen because they belong to the same class as DR1 and have similar structures and molecular weights as DR1 (Fig. 5).

Hence, the antibody selectivity was evaluated in the presence of interfering substances that were very similar to the DR1 antigen. After the incubation step, EIS measurements were performed and the signal $\left(\Delta R_{C T}\right)$ obtained for each dye was compared to the signal obtained for DR1 (considered 100\%) at the same concentration. The results obtained are presented in Fig. 6.

Although the magnitude of the signal observed for DR1 was more than 3 times higher than the signals observed for the other dyes (26.2\% for D01; $28.3 \%$ for DR73; and $22.6 \%$ for DR78), it is clear that the interfering substances induced reactions. The effects were not very pronounced, but nonetheless if a sample contained a mixture of these dyes, the signal observed for DR1 would be slightly higher than the true value. However, given that these molecules are very similar, the results could be considered satisfactory.

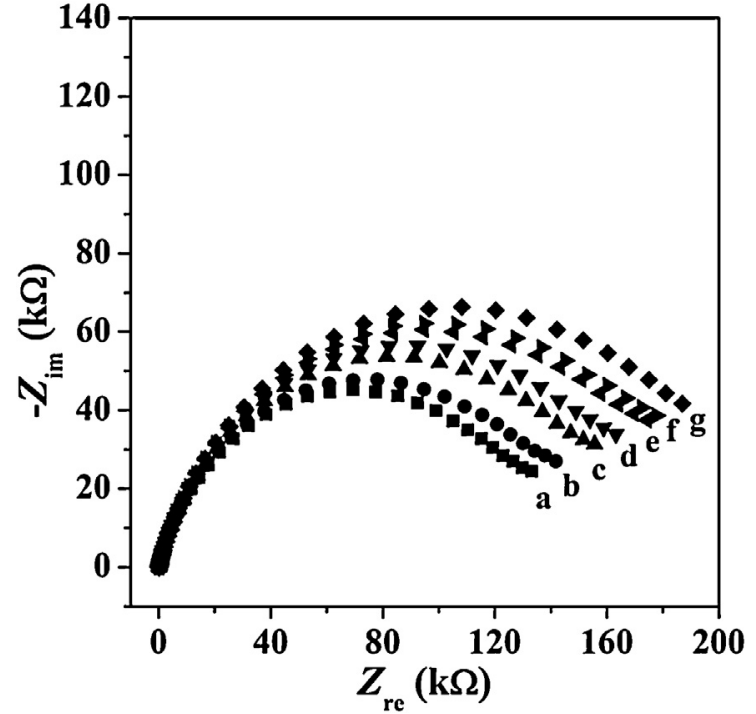

Fig. 7. Nyquist plots for the immunosensor incubated with different concentrations of DR1: (a) blank; (b) $1.0 \mathrm{nM}$; (c) $20.0 \mathrm{nM}$; (d) $40.0 \mathrm{nM}$; (e) $60.0 \mathrm{nM}$; (f) $80.0 \mathrm{nM}$; and (g) $100.0 \mathrm{nM}$.

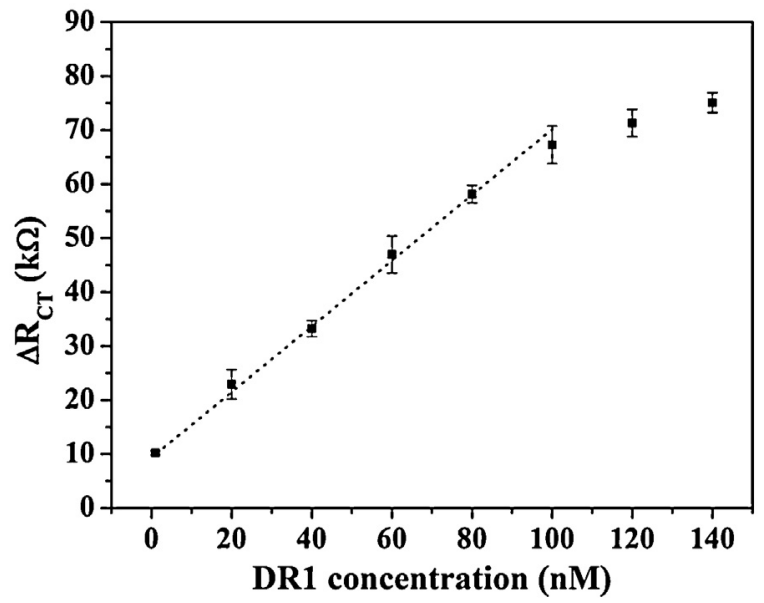

Fig. 8. Calibration curve for DR1. The error bars represent the standard deviation for measurements in triplicate.

\subsection{Detection of disperse Red 1 using the impedimetric immunosensor}

The performance of the immunosensor was evaluated by analysis of the change in $R_{C T}$ values obtained in EIS measurements after the immunoaffinity reaction, using different concentrations of DR1. There was a progressive increase of $R_{C T}$ with increasing DR1 concentration (Fig. 7), since the DR1 molecules attached to the electrode surface increased the kinetic barrier to electron transfer of the redox couple used as a probe.

The immunosensor responses $\left(R_{C T}\right.$ for incubation with DR1 subtracted from the response for incubation with PBS) were plotted against the DR1 concentrations. The calibration curve was constructed in triplicate (Fig. 8) and showed a linear range from 8.40 to $100 \mathrm{nM}$, with saturation at higher DR1 concentrations. The curve was described by the linear regression equation: $\Delta \mathrm{R}_{\mathrm{CT}}(\mathrm{k} \Omega)=9.61+0.59 \mathrm{C}_{\mathrm{DR} 1}(\mathrm{nM})$, with a correlation coefficient $(\mathrm{r})$ of 0.9991 . The limits of detection (LOD) and quantification (LOQ) were 2.52 and $8.40 \mathrm{nM}$, calculated using $3 \mathrm{~s} / \mathrm{S}$ and $10 \mathrm{~s} / \mathrm{S}$, respectively, where $s$ is the standard deviation (root mean square error) 
and $\mathrm{S}$ is the slope. Based on these results, the immunosensor performance was then evaluated using a water sample.

\subsection{Determination of DR1 in a water sample}

The performance of the impedimetric immunosensor was evaluated by determination of the concentration of DR1 present in a water sample. The experiment was first performed with tap water (treated water collected directly from the tap) with no DR1 spiking. The tap water was diluted $1: 5$ in PBS buffer solution $(0.1 \mathrm{M}$, $\mathrm{pH}$ 7.4), and the experimental conditions were the same as used for construction of the calibration curve. There were no differences between the $R_{C T}$ values obtained for incubation in PBS buffer (blank) and for incubation in the sample, indicating that no DR1 was present in the tap water sample. The sample was then spiked with $20.0 \mathrm{nM}$ of DR1, the EIS measurement was carried out and then DR1 determination was performed by standard addition method (incubation in DR1 standard solutions at concentrations of 20.0, 40.0 , and $60.0 \mathrm{nM}$ ). The experiment was performed in triplicate. The $\Delta R_{C T}$ values were obtained and the linear regression, $\Delta R_{C T}$ $(\mathrm{k} \Omega)=11.11+0.56 \mathrm{C}_{\mathrm{DR} 1}(\mathrm{nM})$, was used to calculate the mean DR1 concentration. A value of $19.7 \pm 3.1 \mathrm{nM}$ corresponded to $98.5 \%$ recovery, demonstrating that the immunosensor provided satisfactory performance for the determination of DR1.

\section{Conclusion}

A simple, sensitive, and label-free impedimetric immunosensor is presented for detection of the textile azo dye Disperse Red 1 in treated water. The methodology used for antibody immobilization, based on the generation and activation of carboxylic groups on the glassy carbon electrode surface, is low-cost, employs common reagents, and requires only a few steps. The sensor is demonstrated to be effective and stable. The entire process, including immunosensor construction, electrochemical impedance measurements, and data processing, is not complex and enables the determination of DR1 at low concentrations in practical applications involving water samples. There have been few studies on the literature concerning the use of immunoassays to determine disperse dyes and the proposed method enhances the potential in this area.

\section{Acknowledgements}

The authors thank FAPESP (Processes 2008/10449-7 and 2011/15277-2) and CNPq (Process 309275/2012-1) for financial support.

\section{References}

[1] P. Kariyajjanavara, N. Jogttappaa, Y.A. Nayaka, Studies on degradation of reactive textile dyes solution by electrochemical method, J. Hazard. Mater. 190 (2011) 952-961.

[2] F.M.D. Chequer, T.M. Lizier, R. Felício, M.V.B. Zanoni, H.M. Debonsi, N.P. Lopes, D.P. Oliveira, The azo dye Disperse Red 13 and its oxidation and reduction products showed mutagenic potential, Toxicol. In Vitro 29 (2015) 1906-1915.

[3] S.S. Phugare, D.C. Kalyani, A.V. Patil, J.P. Jadhav, Textile dye degradation by bacterial consortium and subsequent toxicological analysis of dye and dye metabolites using cytotoxicity, genotoxicity and oxidative stress studies, J. Hazard. Mater. 186 (2011) 713-723.

[4] K. Al-Sabti, Chlorotriazine Reactive Azo Red 120 textile dye induces micronuclei in fish, Ecotox. Environ. Saf. 47 (2000) 149-155.

[5] K.T. Chung, C.E. Cerniglia, Mutagenicity of azo dyes: structure-activity relationships, Mutat. Res. 277 (1992) 201-220.

[6] G.A. Umbuzeiro, H. Freeman, S.H. Warren, F. Kummrow, L.D. Claxton, Mutagenicity evaluation of the commercial product CI Disperse Blue 291 using different protocols of the Salmonella assay, Food Chem. Toxicol. 43 (2005) 49-56.
[7] S.R. Macwana, S. Punj, J. Cooper, E. Schwenk, G.H. John, Identification and isolation of an azoreductase from Enterococcus faecium, Curr. Issues Mol. Biol. 12 (2010) 43-48.

[8] S. Pricelius, C. Held, M. Murkurovic, M. Bozic, V. Kokol, A. Cavaco-Paulo, G.M. Guebitz, Enzymatic reduction of azo and indigoid compounds, Appl. Microbiol. Biotechnol. 77 (2007) 321-327.

[9] C.V. Uliana, G.S. Garbellini, H. Yamanaka, Evaluation of the interactions of DNA with the textile dyes Disperse Orange 1 and Disperse Red 1 and their electrolysis products using an electrochemical biosensor, Sens. Actuators B 178 (2013) 627-635.

[10] S. Dwivedi, Effect of textile dyes on Spirulina platensis, J. Chem. Pharm. Res. 5 (2013) 66-80.

[11] X.Q. Yang, X.X. Zhao, C.Y. Liu, Y. Zheng, S.J. Qian, Decolorization of azo, triphenylmethane and anthraquinone dyes by a newly isolated Trametes sp. SQ01 and its laccase, Proc. Biochem. 44 (2009) 1185-1189.

[12] S. Andleeb, N. Atiq, A. Parmar, G.D. Robson, S. Ahmed, An HPLC method development for the assessment of degradation products of anthraquinone dye, Environ. Monit. Asses. 176 (2011) 597-604.

[13] G. Fang, Y. Wu, X. Dong, C. Liu, S. He, S. Wang, Simultaneous determination of banned Acid Orange Dyes and Basic Orange Dyes in foodstuffs by liquid chromatography-tandem electrospray ionization mass spectrometry via negative/positive ion switching mode, J. Agric. Food Chem. 61 (2013) 3834-3841.

[14] K. Lech, M. Jarosz, Novel methodology for the extraction and identification of natural dyestuffs in historical textiles by HPLC-UV-Vis-ESI MS. Case study: chasubles from the Wawel Cathedral collection, Anal. Bioanal. Chem. 399 (2011) 3241-3251.

[15] T. Zou, P. He, A. Yasen, Z. Li, Determination of seven synthetic dyes in animal feeds and meat by high performance liquid chromatography with diode array and tandem mass detectors, Food Chem. 138 (2013) 1742-1748.

[16] N. Dossi, R. Toniolo, A. Pizzarielo, S. Susmel, F. Perennes, G. Bontempelli, A capillary electrophoresis microsystem for the rapid in-channel amperometric detection of synthetic dyes in food, J. Electroanal. Chem. 601 (2007) 1-7.

[17] Y. Dong, J. Zhang, Y. Xing, Z. Song, Y. Wang, M. Meng, C. Deng, Z. Tong, Y. Yin, R. Xi, Quantification of Ponceau $4 \mathrm{R}$ in foods by indirect competitive enzyme-linked immunosorbent assay (icELISA), J. Agric. Food Chem. 63 (2015) 6338-6345.

[18] B. Zhang, D. Du, M. Meng, S.A. Eremin, V.B. Rybako, J. Zhao, Y. Yin, R. Xi, Determination of amaranth in beverage by indirect competitive enzyme-linked immunosorbent assay (ELISA) based on anti-amaranth monoclonal antibody, Food Anal. Method. 7 (2014) 1498-1505.

[19] X. Ye, Y. Du, D. Lu, C. Wang, Fabrication of -cyclodextrin-coated poly(diallyldimethylammonium chloride)-functionalized graphene composite film modified glassy carbon-rotating disk electrode and its application for simultaneous electrochemical determination colorants of sunset yellow and tartrazine, Anal. Chim. Acta 779 (2013) 22-34.

[20] F.F. Hudari, L.C. Almeida, B.F. Silva, M.V.B. Zanoni, Voltammetric sensor for simultaneous determination of p-phenylenediamine and resorcinol in permanent hair dyeing and tap water by composite carbon nanotubes/chitosan modified electrode, Microchem. J. 116 (2014) 261-268.

[21] P. Zhao, J. Hao, 2,6-Diaminopyridine-imprinted polymer and its potency to hair-dye assay using graphene/ionic liquid electrochemical sensor, Biosens. Bioelectron. 64 (2015) 277-284.

[22] F. Xiao, N. Zhang, H. Gu, M. Qian, J. Bai, W. Zhang, L. Jin, A monoclonal antibody-based immunosensor for detection of Sudan I using electrochemical impedance spectroscopy, Talanta 84 (2011) 204-211.

[23] J. Yang, C.G. Rocha, S. Wang, A.A.P. Ferreira, H. Yamanaka, A label-free impedimetric immunosensor for direct determination of the textile dye Disperse Orange 1, Talanta 142 (2015) 183-189.

[24] R. Saber, Z. Karimi, M. Shamsipur, A novel antobody-antigen based impedimetric immunosensor for low level detection of HER2 in serum samples of breast cancer patients via modification of a gold nanoparticles decorated multiwall carbono nanotube-ionic liquid electrode, Sens. Actuators B 874 (2015) 66-74.

[25] L. Zhang, M. Wang, X. Hu, G. Wang, Label-free impedimetric immunosensor for sensitive detection of 2,4-dichlorophenoxybutyric acid (2,4-DB) in soybean, Talanta 101 (2012) 226-232.

[26] G. Bacher, S. Pal, L. Kanungo, S. Bhand, A label-free silver wire based impedimetric immunosensor for detection of aflatoxin M1 in milk, Sens. Actuators B 168 (2012) 223-230

[27] A.A. Ansari, A. Kaushik, P.R. Solanki, B.D. Malhotra, Nanostructured zinc oxide platform for mycotoxin detection, Bioelectrochemistry 77 (2010) 75-81.

[28] G. Yang, W. Jin, L. Wu, Q. Wang, H. Shao, A. Qin, B. Yu, D. Li, B. Cai, Development of an impedimetric immunosensor for the determination of 3-amino-2-oxazolidone residue in food samples, Anal. Chim. Acta 706 (2011) $120-127$.

[29] A. Johnson, Q. Song, P.K. Ferigno, P.R. Bueno, J.J. Davis, Sensitive affimer and antibody based impedimetric label-free assays for C-reactive protein, Anal. Chem. 84 (2012) 6553-6560.

[30] M. Tang, S. Chen, R. Yuan, Y. Chai, F. Gao, Y. Xie, Amperometric biosensor for hydrogen peroxide based on direct electrocatalysis by hemoglobin immobilized on gold nanoparticles/1,6-diaminohexane modified glassy carbon electrode, Anal. Sci. 24 (2008) 487-491.

[31] S. Samanman, P. Kanatharana, P. Asawatreratanakul, P. Thavarungkul, Characterization and application of self-assembled layer by layer gold 
nanoparticles for highly sensitive label-free capacitive immunosensing, Electrochim. Acta 80 (2012) 202-212.

[32] V. Bhalla, P. Sharma, S.K. Pandey, C.R. Sury, Impedimetric label-free immunodetection of phenylurea class of herbicides, Sens. Actuators B 171-172 (2012) 1231-1237.

[33] L.T.N. Truong, M. Chikae, Y. Ukita, Y. Takamura, Labelless impedance immunosensor based on polypyrrole-pyrolecarboxylic acid copolymer for hCG detection, Talanta 85 (2011) 2576-6580.

[34] A.D. Chowdhury, A. De, C.R. Chaudhuri, K. Bandyopadhyay, P. Sen, Label free polyaniline based impedimetric biosensor for detection of E. coli O157:H7 Bacteria, Sens. Actuators B 171-172 (2012) 916-923.

[35] K.M. Millan, S.R. Mikkelsen, Sequence-selective biosensor for DNA based on hybridization indicators, Anal. Chem. 65 (1993) 2317-2323.

[36] U. Jarocka, R. Sawicka, A. Gora-Sochacka, A. Sirko, W. Zagorski-Ostoja, J. Radecki, H. Radecka, Electrochemical immunosensor for detection of antibodies against influenza A virus H5N1 in hen serum, Biosens. Bioelectron. 55 (2014) 301-306

[37] S.L. Ellison, V.J. Barwick, T.J.D. Farrant, Practical Statistics for the Analytical Scientist: A Bench Guide, The Royal Chemistry Society, Amsterdam, 2009, pp. 114-143 (ch. 8)

[38] A.A.P. Ferreira, C.S. Fugivara, S. Barrozo, P.H. Suegama, H. Yamanaka, A.V. Benedetti, Electrochemical and spectroscopic characterization of screen-printed gold-based electrodes modified with self-assembled monolayers and Tc85 protein, J. Electroanal. Chem. 634 (2009) 111-122.

[39] G. Socrates, Infrared and Raman Characteristic Group Frequencies, 3rd ed., John Wiley \& Sons, Chichester, 2001, pp. 328-340 (ch. 23).
[40] R.M. Silverstein, F.X. Webster, D.J. Kielme, Identificação Espectrométrica De Compostos Orgânicos, 7th ed., LTC, Rio de Janeiro, 2006, pp. $70-76$ (ch. 2).

[41] A.A.P. Ferreira, M.J.M. Alves, S. Barrozo, H. Yamanaka, A.V. Benedetti, Optimization of incubation time of protein Tc85 in the construction of biosensor: is the EIS a good tool? J. Electroanal. Chem. 643 (2010) 1-8.

\section{Biographies}

Carolina Gomes da Rocha received her Chemistry degree (2011) and a Master's degree in Chemistry (2014) from Universidade Estadual Paulista (UNESP) in Araraquara, São Paulo (Brazil). Her research area is focused in analytical chemistry/electroanalytical more specifically in the construction of electrochemical biosensors for the detection of environmentally relevant substances and for clinical diagnosis.

Antonio Aparecido Pupim Ferreira studied Pharmaceutical Sciences, Unesp, Araraquara, São Paulo (Brazil). In 2002 and 2005 obtained her Master's and PhD degrees in Biotechnology, respectively (Unesp, Brazil). Works with the development of electrochemical biosensors.

Hideko Yamanaka: associated professor at São Paulo State Univesity, Institute of Chemistry in Araraquara, Brazil. The research activity is focused on development of amperometric and impedimetric biosensors. 